\title{
Assessing differential effects of implementation quality and risk status in a whole-school social and emotional learning programme: Secondary SEAL
}

\author{
Michael Wigelsworth*, Ann Lendrum, Neil Humphrey
}

Educational Support and Inclusion, School of Education, University of Manchester, M139PL, UK

Received 13 December 2012; received in revised form 20 May 2013; accepted 18 June 2013

\section{KEYWORDS}

Social and emotional learning;

Whole-school;

Secondary school;

Intervention;

Implementation;

Risk status

\begin{abstract}
This study examines differences in impact of the secondary social and emotional aspects of learning (SSEAL) programme through (i) pupils with low, average and high Emotional Literacy (EL) skills and (ii) variation in implementation quality. Data from a 2-year, quasiexperimental pre-test-post-test design was used, consisting of 3306 pupils (aged 11-12 years) attending 41 English secondary schools. Data was collected using (i) self-report measures (Emotional Literacy: Assessment and Intervention (ELAl) inventory) and (ii) longitudinal, qualitative methods. Results showed (i) no significant improvements for any EL group and (ii) no effect of implementation quality. Recommendations for future research are also presented.

(c) 2013 Elsevier $\mathrm{GmbH}$. All rights reserved.
\end{abstract}

\section{Introduction}

Concerns about the emotional wellbeing of children and young people have risen over the last 20 years (Collishaw, Maughan, Natarajan, \& Pickles, 2010). Current estimates suggest that one in 10 young people experience clinically significant problems, with higher rates of disorder among adolescents than children (Green, McGinnity, Melzer, Ford, \& Goodman, 2005), and many cases remaining undiagnosed and/or untreated (Macdonald \& Bower, 2000; Meltzer et al.,

\footnotetext{
*Corresponding author. Tel.: +44161306 1763.

E-mail address: michael.wigelsworth@manchester.ac.uk (M. Wigelsworth).
}

2000). This is an obvious concern for educational professionals given the negative impact that poor emotional health can have on educational outcomes such as attendance and exclusion rates (Meltzer et al., 2000; Petrides, Fredrickson, \& Furnham, 2004), attainment (Parker et al., 2004) quality of life (Rothi \& Leavey, 2008) and happiness (Furnham \& Petrides, 2003). Furthermore, if untreated, problems may persist and develop into psychological difficulties in adulthood (Stallard, 2011).

Given the central role of schools in the lives of children and families (Greenberg, 2010), the perceived importance of the school in addressing mental health needs has increased, as evidenced by the rapid deployment of preventive social and emotional learning (SEL) interventions across the world (Heys, 2011; Department for Education and 
Skills, 2005; Department for Children, Schools, and Families, 2007; Graetz et al., 2008). Although some interventions provide targeted provision for pupils requiring specific support (e.g. those already experiencing symptoms), programmes typically utilise a 'universal' delivery model that is for all pupils, regardless of any specific need. The prevailing theory underpinning a universal approach is to prevent the development of mental health problems through the teaching and modelling of strategies to promote social and emotional health and wellbeing, effectively 'immunising' vulnerable children against later difficulties (Merrell \& Gueldner, 2010). This approach is favoured over more intensive interventions as it is more cost effective to implement as there is no need for screening 'at risk' children. Also, evaluations have shown that teachers and school staff can be trained to deliver programmes in place of external professionals (Stallard, Simpson, Anderson, Hibbert, \& Osborn, 2007), improving sustainability.

Several systematic reviews (Adi, 2007; Blank et al., 2009; Weare \& Nind, 2010) and meta-analyses (Durlak, Weissberg, Dymicki, Taylor, \& Schellinger, 2011; Wilson \& Lipsey, 2007) in this area have demonstrated that high-quality SEL interventions can impact on a range of outcomes (including social and emotional skills, mental health difficulties, school attitudes and academic performance). Significant effects in the small-to medium range that are likely to be of practical significance have been demonstrated, and are enhanced among those programmes that conform to established success criteria (see Durlak et al., 2011; Durlak, Weissberg, \& Pachan, 2010) and where implementation quality is high (Durlak \& DuPre, 2008; Greenberg et al., 2005). However, evidence for the success of universal prevention programmes is still not conclusive (Durlak et al., 2011). For example, a recent large-scale study reported no discernible effect across several well-known SEL programmes (Social and Character Development Research Consortium, 2010).

Several explanations have been presented in an attempt to explain conflicting findings, including methodological limitations (see Wigelsworth, Humphrey, \& Lendrum, 2011) and implementation variability. Implementation refers to the putting into practice of an innovation or intervention and is typically assessed in relation to constructs such as fideltity of delivery and dosage (Durlak \& DuPre, 2008; Domitrovich, Gest, Jones, Gill, \& Sanford-DeRousie, 2010; Kam, Greenberg, \& Walls, 2003; Lendrum \& Humphrey, 2012). At a theoretical level, current literature has not empirically explored some of the underlying assumptions of the logical model of preventative intervention. For instance, SEL programmes typically operate a 'universal gains' model in which successful impact is measured by improvements in social and emotional skills in all pupils involved in the intervention. If no significant differences or very small effect sizes are found when compared to usual practice, then the intervention is typically considered to be ineffective. However, there is a fallacy of logic in this approach, as the universal gains model implies that all pupils will benefit equally from the intervention. As Greenberg (2010) points out, most children will not be experiencing difficulties at the outset of a universal intervention. Given the prevalence of undiagnosed mental health difficulties in a minority of pupils (Macdonald \& Bower, 2000), results from studies may therefore represent the proportion of children who required the intervention to raise their social and emotional competencies to 'normative' levels, rather than the overall effectiveness of the intervention itself. In other words, the greater the need of the student body, the more effective the intervention may appear to be. One problem with this interpretation is that classrooms with high levels of disruption or need can interfere with the implementation of a programme, leading to reduced impact (Hughes, Cavell, Meehan, Zhang, \& Collie, 2005). Nonetheless, it does raise the possibility that a 'diminishing effects' rather than 'universal gains' model may be an explanation for conflicting findings.

The aim of this paper is to explore the issues raised above using data from a large scale national evaluation of an SEL intervention. Our research provides a response to recent calls for appropriate sub-group analyses in prevention research, which has generally been lacking to date (Durlak et al., 2011; Humphrey, 2013). The only examples of such analyses that the authors have been able to find in the extant literature have all been for programmes incorporating universal and targeted/ indicated approaches (e.g. Conduct Problems Prevention Research Group, 1999; Slee et al., 2009; Wilson \& Lipsey, 2007). We are unaware of any evaluation of a universal SEL intervention in which differential effects have been modelled as a function of pre-test risk status.

\section{The social and emotional aspects of learning (SEAL) programme for secondary schools}

Secondary SEAL is a whole-school, universal intervention designed to 'promote the social and emotional skills that underpin effective learning... [and]...positive behaviour' (Department for Children, Schools and Families, 2007, p. 4). SEAL is based on the theory of Emotional Intelligence (EI) originally proposed by Goleman (1996), and centres on five key skills: self-awareness, self-regulation (managing feelings), motivation, empathy and social skills. SEAL may be classed as a 'multi-component' intervention as the materials include whole school assemblies, class activities and suggestions to include the wider community. These activities are promoted through four interrelated components, specifically:

- A whole school approach: key components include policy development, active partnerships with parents and the community, promoting a positive school culture, and giving students a voice (Department of Health, 2007).

- Direct teaching of social and emotional skills: the SEAL materials contain a series of sessions, organised in discrete themes, based on the El framework (e.g. 'learning about me - managing feelings, keep on learning motivation). The materials are designed to be taught throughout the year by a facilitator (e.g. teacher or teaching assistant).

- Teacher modelling of behaviour and learning approaches that is consistent with the SEAL framework: this includes promoting pedagogical approaches such as teamwork, co-operative and group projects, as a means of implicitly promoting social skills (Department for Children, Schools and Families, 2007).

- Continuing professional development for staff: examples include coaching and mentoring, training in specific 
areas (e.g. anger management) and provision of a SEAL working party to promote the programme in school (Department for Children, Schools and Families, 2007).

Unlike many existing SEL interventions, secondary SEAL is characterised by its flexibility, with schools encouraged to tailor it to their own specific context and requirements (Department for Children, Schools, and Families, 2007). One the one hand, this approach confers considerable advantages, inasmuch as it is more respectful of the autonomy and professionalism of school staff, recognises that there is no 'one size fits all' approach to SEL, and can encourage local ownership and sustainability. However, it also potentially leaves schools without a clear 'roadmap' to follow, which is a major risk factor for implementation failure. It also makes assessment and monitoring if implementation (e. g. fidelity) rather challenging. Full details on the programme, including guidance materials, can be freely accessed at http://tinyurl.com/cokjht6.

Although different versions of secondary SEAL have been evaluated in England on several occasions (e.g. Humphrey, Lendrum, \& Wigelsworth, 2010; Ofsted, 2007; Smith, O’Donnell, Easton, \& Rudd, 2007), these have not considered differential gains in social and emotional skills as a function of risk status, or modelled gains in relation to implementation quality. On this basis, the research questions for the current study are

- RQ1 - What is the impact of the secondary SEAL programme on pupils with low (at-risk), average, and high social and emotional skills?

- RQ2 - Do the proportional odds of moving out of at-risk status from pre-test to post-test vary as a function of exposure to secondary SEAL?

- RQ3 - For pupils exposed to secondary SEAL, does schoollevel implementation quality mediate impact?

\section{Method}

\section{Design}

A pre-test-post-test control group design was adopted. The two explanatory variables of the study were 'SEAL status' (whether a school was implementing SEAL or part of a 'usual practice' comparison group) and pre-test social and emotional skills classification (low, average and high - see Measures). The response variable was change in pupils' social and emotional skills over the course of the trial.

\section{Sample}

All participants were secondary school pupils in Year 7 (aged 11-12 years of age at the time of pre-test), attending schools across 25 Local Authorities (LAs) in England. As the initial 26 SEAL schools had been recruited before the research was commissioned, random allocation was not possible. Instead, a sample of 23 comparison schools were recruited and matched to SEAL schools on the basis of similar attainment, free school meal eligibility, proportion of children receiving special educational needs provision, attendance and size. Attrition over the course of the study left 22 SEAL and 19 matched comparison schools and a final sample of 3306 pupils (1802 SEAL, 1504 control). A subsample of nine of the 22 SEAL schools agreed to participate in additional data collection focusing on implementation quality (see below).

Based on previous literature (Humphrey et al., 2008), the final sample of the current study far exceeded the minimum threshold for detecting a small effect $\left(f^{2}=0.02\right)$, which required a minimum of 543 pupils (assuming Power $=0.80$ and $\alpha=0.05$ - Cohen, 1992).

\section{Measures}

\section{Social and emotional skills}

Changes in pupils' social and emotional skills were assessed using the Emotional Literacy Assessment and Intervention (ELAI) survey (Southampton Psychology Service, 2003). For use with children aged 7-16 years, this self-report instrument consists of 25 items (e.g. 'I worry a lot about the things I am not good at') to which participants respond using a four-point Likert scale (very much like me/quite like me/ only a bit like me/not like me at all). The ELAl takes approximately 5-10 min to complete. Each respondent receives a score ranging from 25 to 100 . Previous validation work on the instrument (Southampton Psychology Service, 2003) provides threshold/banding scores, with a score of 84 or above as 'well above average', scores between 83 and 62 as average, and scores of 61 or below as being considered 'well below average'. The inventory's authors consider the category of 61 or below as low enough to require intervention (hence the designation of 'at-risk' for pupils scoring in the low banding).

The ELAl is based on the same theoretical framework as SEAL (Goleman, 1996), meaning that the five key competencies promoted in the SEAL programme (self-awareness, self-regulation, motivation, empathy and social skills) are assessed by the instrument. The ELAl has satisfactory internal consistency, with a Cronbach's alpha co-efficient of 0.75 (Southampton Psychology Service, 2003). The ELAI has been shown to be change-sensitive in evaluations of other SEL interventions (Humphrey et al., 2008) and has been recommended for use by the English government (Department for Education and Skills, 2006).

\section{Implementation quality}

As noted above, a subsample of nine SEAL schools agreed to participate in additional data collection focusing on implementation quality. The open-ended and flexible nature of the SEAL intervention meant that typical measures of implementation quality could not be used (e.g. there is no single agreement of 'fidelity' as there was no prescribed model for implementation). Instead, a qualitative approach was taken, with longitudinal case studies of each school conducted over a 2-year period, involving interviews with staff, focus groups with students, observations and document analysis, detailed reports of which are available elsewhere (Humphrey et al., 2010; Lendrum, Humphrey, \& Wigelsworth, in press). This data was used to create summary judgements about the progress of implementation in each school, relative to one another. The nine SEAL 
schools were categorised into three implementation clusters: higher quality $(N=4)$, moderate quality $(N=3)$, and lower quality $(N=2)$. Higher quality schools were those where data suggested that good progress had been made and a comprehensive approach to implementation had been attempted (e.g. clear evidence of activity in the areas described earlier in this article). Moderate quality schools displayed some success, but progress in implementation was mixed or inconsistent (e.g. there was no evidence of progress in all areas of activity). Finally, lower quality schools were those where there was little to no evidence of sustained progress in any area of activity.

\section{Procedure}

Survey data from pupils in participating schools was collected at the beginning of 2008 (pre-test), and 2 years later at the beginning of 2010 (post-test). A wave of data collection also took place in 2009 , but was used solely for interim reporting purposes. For each wave of data collection, participating schools were sent a pack of pupil questionnaires with administration instructions. In each school, a member of staff took responsibility for coordinating the completion of the questionnaires by pupils (in SEAL schools, this was the designated programme lead; in comparison schools, it was typically the head of year or pastoral care coordinator). Administration of the questionnaires took place in either whole-year (e.g. year assembly) or whole-class (e.g. tutor group) settings. Any pupils who had difficulties in completing the questionnaires (e.g. because of poor literacy) were able to solicit support from an appropriate member of staff. Tracking of individual responses over time was achieved through the use of personalised labels on questionnaires that included pupils names and a unique numerical identifier. This information was used solely for accurate matching and was destroyed once this had been achieved. Once complete, the questionnaires were collected by courier and delivered to an independent company who scored and input the data into an electronic database ready for analysis. Both the independent company and the authors conducted random quality checks (e.g. comparison of hard and electronic copy data for the same pupil) to ensure accuracy of scoring.

\section{Results}

\section{Data screening}

Consistent with recommendations of best practice (Peugh \& Enders, 2004; Roth, 1994; Wilkinson, 1999), data were comprehensively screened in the interests of rigour, validity and representativeness.

No discernible differences were found between schools that dropped out of the study and the final sample. Analysis of variance demonstrated that the SEAL and comparison groups did not significantly differ from one another in any of the case-control variables used to match the schools (all $p>$.05). One sample $t$-tests confirmed the lack of significant differences between SEAL/comparison schools and national averages in all variables except size, with SEAL schools being slightly larger than is typical.

Chi-square analyses demonstrated that the SEAL and comparison pupil groups did not significantly differ from one another in regards to gender or free school meal eligibility. Although there was a significantly smaller proportion of children identified as having special educational needs in SEAL schools, the percentage difference was very small (approximately 5\%). Similarly, there was a 5\% difference in the number of pupils being reported as White British compared to other ethnicities in the SEAL schools.

Tabulated pattern analysis revealed that less than $1 \%$ of missing cases for the response variable could be attributed to differences in the case-control variables between schools or as a result of gender, ethnicity, SEN provision status and FSM eligibility. It was therefore concluded that there were no discernible patterns to missing data by item, time or school and pupil characteristics.

\section{Findings}

RQ1 - What is the impact of the secondary SEAL programme on pupils with low (at-risk), average, and high social and emotional skills?

Means and standard deviations of each of the ELAl groups in both SEAL and comparison schools are shown in Table 1.

To investigate changes in pupils' scores over time, data were analysed using a $3 \times 2$ between-participants analysis of variance (ANOVA) with ELAl pre-test classification (low, average, high) and school type (SEAL or comparison) as explanatory variables and ELAl change (post-test minus pretest) as the response variable.

Consistent with previous analyses (Wigelsworth et al., 2011), no significant effect of school type (SEAL vs. comparison) was found, $F(1,3300)=2.349, p>.05, \eta^{2}=.001$. However, a main effect of ELAl pre-test classification (low vs. average vs. high) was found, $F(2,3300)=355.769$, $p<.01, \eta^{2}=177$. Post-hoc analysis revealed significant differences in ELAl change scores between the low and average group (mean difference 8.04), low and high group (mean difference 14.27) and average and high group (mean

Table 1 Means and standard deviations of SEAL and comparison schools for each ELAl category (pre- and post-test).

\begin{tabular}{llllll}
\hline & \multicolumn{2}{l}{ SEAL school } & & & \multicolumn{2}{l}{ Comparison school } \\
\cline { 2 - 3 } & Pre-test & & Post-test & & Post-test \\
\cline { 5 - 6 } & $57.23(3.68)$ & $64.58(7.61)$ & & $57.13(3.86)$ & $64.89(6.90)$ \\
Low skills $(<61)$ & $73.04(5.45)$ & $72.84(7.33)$ & & $73.12(5.35)$ & $72.23(7.18)$ \\
Average skills & $86.35(3.03)$ & $80.28(7.39)$ & & $86.73(3.35)$ & $79.20(8.29)$ \\
High skills $(>84)$ & & &
\end{tabular}


Table 2 Frequencies and percentages of SEAL and comparison schools for each ELAl category (pre and post-test).

\begin{tabular}{|c|c|c|c|c|}
\hline & \multicolumn{2}{|l|}{ SEAL school } & \multicolumn{2}{|c|}{ Comparison school } \\
\hline & Pre-test & Post-test & Pre-test & Post-test \\
\hline Low skills $(<61)$ & $161(8.9 \%)$ & $134(7.4 \%)$ & $118(7.8 \%)$ & $106(7.0 \%)$ \\
\hline Average skills & $1358(75.4 \%)$ & 1474 (81.8\%) & $1144(76.1 \%)$ & $1260(83.8 \%)$ \\
\hline High skills $(>84)$ & 283 (15.7\%) & 194 (10.8\%) & $242(16.1 \%)$ & $138(9.2 \%)$ \\
\hline
\end{tabular}

difference 6.23) (all $p<.05$ ). There was no interaction effect between ELAl pre-test classification and school type, $F(2,3300)=1.495, p>.05, \eta^{2}=.001$. This finding suggests that the SEAL intervention did not have a differential impact on pupils with differing pre-test levels of social and emotional skills.

RQ2 - Do the proportional odds of moving out of at-risk status from pre-test to post-test vary as a function of exposure to secondary SEAL?

Although social and emotional skills were seen to change over the period of the intervention, change in mean scores could not be directly attributed to the SEAL programme in the three ELAl pre-test classification groups. However, assessing the likelihood of moving from an 'at risk' category into a category of less concern is arguably of more utility for school-based interventions, and is consistent with the advice presented in the ELAl manual, which notes that students scoring less than 61 (the 'low' category in the current study) are in need of intervention. On this basis, the odds ratio (Ellis, 2010) of moving out of the low category (into either average of high) over the duration of the study is considered.

Frequency and percentage values of each of the ELAI pretest classification groups for both SEAL and comparison schools are shown in Table 2.

As can be seen from Table 2, the prevalence of pupils with low ELAl scores in the SEAL group was $8.9 \%$, slightly lower than the $10 \%$ suggested by the normalisation sampling in the original manual (Southampton Psychology Service, 2003). The prevalence of pupils in the low group reduced at post-test to $7.4 \%$. By measuring the proportion of children who remained in the low category, an odds ratio of 0.33 is produced, meaning that approximately one-third of the children initially in the low category within SEAL schools remained in this category at post-test.

A similar proportion of change is reported in the comparison group, as the prevalence of pupils with low EL scores in the pre-test group was $7.8 \%$, with a reduction to $7 \%$ at the post-test measures. Accounting for pupils remaining in the low category at post-test, this change has an associated odds ratio of .30. This means that, similar to the SEAL group, approximately a third of children in the comparison schools moved out of the low category over the period of the study.

In order to assess the incremental validity of the SEAL programme over gains made through normal practice and/or maturation in the school system (as represented by the comparison schools), the odds ratios can be directly compared by dividing the SEAL odds ratio by the comparison ratio. A value close to 1 would indicate that
Table 3 Descriptive statistics for pupils in schools rated as high, moderate and low in overall implementation quality.

\begin{tabular}{llll}
\hline & Low & Moderate & High \\
\hline ELAl (pre-test) & $75.19(9.63)$ & $74.33(8.69)$ & $74.00(8.60)$ \\
ELAl (post test) & $73.55(9.07)$ & $73.58(7.45)$ & $73.67(8.90)$ \\
\hline
\end{tabular}

belonging to a SEAL or comparison school does not affect the likelihood of moving from the low EL risk category (Ellis, 2010). Comparison of the overall odds ratio provides a figure of .91 meaning that there is a very little effect of belonging to a SEAL school in reducing the prevalence of low El compared to usual practice in the current school system.

RQ3 - For pupils exposed to secondary SEAL, does schoollevel implementation quality mediate impact?

Pupil data for the nine SEAL schools participating in the additional data collection focusing on implementation were extracted for further analysis. In order to address Research Question 3, descriptive statistics were examined (see Table 3), which indicated no implementation effect. The data were then examined using factorial analysis of variance, which tested the relationship between implementation quality (higher, moderate, lower) and changes in student outcome over time (pre-test to post-test). There was no significant interaction between implementation quality and time for social and emotional skill scores $[F(2,565)=0.715, p=.49]$.

\section{Discussion}

The current study set out to investigate the impact of the secondary SEAL programme on pupils with differing levels of social and emotional skills. There was no significant interaction found between school type (SEAL vs. comparison) and ELAI pre-test classification, suggesting that the SEAL programme was not effective in improving skills in any of the groups. This is consistent with the proportional odds analysis, which suggested that there was only a negligible difference in the likelihood of a pupil moving out of the at-risk group over a 2-year period as a result of attending a SEAL, rather than a comparison school. Our analyses also indicated that there were no differences in impact as a result of implementation quality, although sample size limitations prevented further investigation in relation to pre-test ELAl classification (that is, there were insufficient 
participants in certain sub-groups to enable a robust analysis that considered implementation variability and risk status concurrently).

The findings of the current study are in contrast to reviews of the SEL literature (Adi, 2007; Catalano, Berglund, Ryan, Lonczak, \& Hawkins, 2004; Durlak et al., 2011). However, as previously noted, prior reviews have not necessarily considered sub-group of analysis on the basis of baseline risk classification. As the data suggests that SEAL was ineffective for all groups, it is difficult to provide evidence for either a universal gains or diminishing effects model. However, there are useful findings both in relation to developing future research in the UK context, and broader implications for future evaluations.

A worthwhile finding from the current study is the estimate of the number of pupils who can be categorised as requiring intervention. The percentage is somewhat smaller than those suggested by previous authors (Green et al., 2005), who estimate difficulties to be closer to $10 \%$. This is also consistent with Greenberg (2010), who suggests that the majority of children may not require intervention. However, this difference may be attributable to the differences in the measures used as Green et al. report mental health, of which social and emotional skills are a proxy. In relation to measures of social and emotional skills in particular, the estimates from the current sample are lower than those reported by developers of the ELAl (Southampton Psychology Service, 2003) who report that, using the norms of the standardisation sample, approximately $10 \%$ of secondary aged pupils are likely to report very low social and emotional skills. There are several explanations for this variation. First, the normalisation sample used by the ELAl was approximately a third of the size of the current sample, and drawn from a single area. This may suggest that the current study represents a more accurate estimate of the prevalence of low social and emotional skills in early adolescence. Second, the sample used by Southampton Psychology Service used a wider range of ages (11-16 years of age), perhaps suggesting that changes later in school life led to a decline in skills - something not measured by the current study. This would be contrary to the suggested trajectory shown in the current data, as the data in Table 1 suggest a regression to the mean (Barnett, van der Pols, \& Dobson, 2005). This would explain the differences between the relatively static prevalence figures (e.g. approximately $7 \%$ of pupils in the 'at risk' category at pre- and post-test) compared to the lower proportional odds values (approximately .3), indicating that for pupils moving out of the at risk category were replaced by others entering it by post-test. In any case, this suggests a need for further study into the normal trajectory of self-reported social and emotional skills in order to further develop intervention programmes.

In relation to the importance of implementation, findings from the current study suggest that quality of implementation was not related to programme impact. However, the flexibility with which schools can choose to implement the SEAL programme is in stark contrast to more rigid or prescribed programmes, which is noted as a crucial factor in programme impact (Catalano et al., 2004). In this way, there is little consistent fidelity data with which to compare the results, although qualitative data from the main trial suggests implementation may be one factor in explaining null results.
In regards to differential or sub group analysis, this is both a strength and weakness of the design. It is often demonstrated that categorisation of scale data leads to a loss of power and potentially misleading results (MacCallum, Zhang, Preacher, \& Rucker, 2002). However, the authors argue that with careful consideration such appropriate rationale and selection of groups (Agresti, 2007), this is a potentially important aspect of future SEL evaluation. Further use of this technique may be helpful in detecting differential effects, allowing a more in-depth examination and collection of empirical data to support the logic of the 'universal gains', especially for studies that do not have sufficient power for regression based models.

The findings of this study yield important lessons for the future development of initiatives in SEL and related areas. While they do not suggest that preventive interventions like SEAL have no value or place in education, they do imply that there needs to be room for discussion of what can be avoided or improved upon before programmes of this scale and cost are embarked upon. We tentatively suggest that there needs to be proper trialling of interventions to demonstrate efficacy before they are brought to scale, better use of research to inform programme design (for example, how best to balance prescriptiveness and flexibility to effectively 'get the best of both worlds'), and a clearer focus on the importance of implementation quality in programme guidance and training (see Humphrey, Lendrum \& Wigelsworth, in press).

\section{Limitations}

There are some limitations in interpreting our findings. Although the ELAI displays acceptable psychometric properties for overall social and emotional skills, there was a missed opportunity to utilise the sub-domains of selfawareness, self regulation, motivation, empathy and social skills, due to low Cronbach's alpha for the these sub-scales (.47-.68). It is possible that small effects may have been found in particular domains. However, this is considered unlikely given the time period of the intervention meant that there was ample time for the SEAL programme to produce a measurable impact in multiple domains.

The study was also limited by the use of only self-report data, as alternate versions of the ELAl feature both teacher and parent informant-report. A lack of triangulation from other sources means that the null results cannot be corroborated, and this creates the potential for a type II error. However, self-report is a common feature of a majority of SEL evaluations (Durlak et al., 2011), and although triangulation could have offered different perspectives, use of teacher and parent data would have been unlikely to have yielded similar sample sizes due to noncompliance and attrition.

As noted in the Method section, for reasons beyond our control it was not possible to randomise schools to intervention and control conditions. Although our SEAL and comparison schools were well matched, the possibility of a contamination effect at the level of whole-school ethos may have occurred. That is, even though comparison schools were not signed up to implement SEAL, their ethos may have changed via government or Local Authority 
influence. However, we consider this to be unlikely, and furthermore it does not detract from the lack of any 'added value' effect of introducing the SEAL programme to influence pupil outcomes above and beyond the change achieved through standard practice in schools (which must always be the starting point for comparison with any new initiative).

A final consideration is the lack of direct contextual data in regards to the overall quality of the schools. Although issues of behaviour and disruption have been linked to both implementation and impact of programmes (Hughes et al., 2005), such data were not gathered in the current study. The authors suggest that this may a factor of interest in future designs as is likely to be closely related to variations in implementation quality and impact, especially in any subgroup analyses.

\section{Conclusions}

This study has demonstrated null results for the impact of a universal prevention programme aimed at secondary school children. However, in doing so, directions for the future assessment and evaluation of SEL programmes have been presented, specifically the examination of differential effects for at-risk groups. This has important implications for future studies, both in terms of accurate evaluation, but also in producing evidence for diminishing effects or universal gains models. However, this comes with the important caveat of potential loss of power when alternative regression models are available.

\section{Conflict of interest}

The author(s) declared no potential conflicts of interest with respect to the research,authorship, and/or publication of this article.

\section{Funding}

The authors received financial support, awarded as part of an open tender, from the Department of Education (a department of the United Kingdom Government) with respect to the research conducted in the current article. No financial support was provided for the authorship or publication of the article.

\section{References}

Adi, Y. (2007). Systematic review of the effectiveness of interventions to promote mental wellbeing in children in primary education. Warwick: University of Warwick.

Agresti, A. (2007). An introduction to categorical data analysis. New Jersey: Wiley.

Barnett, A. G., van der Pols, J. C., \& Dobson, A. J. (2005). Regression to the mean: What it is and how to deal with it. International Journal of Epidemiology, 34, 215-220.

Blank, L., Baxter, S., Goyder, E., Guillaume, L., Wilkinson, A., Hummel, S., \& Chilcott, J. (2009). Promoting wellbeing by changing behaviour: A systematic review and narrative synthesis of the effectiveness of whole secondary school behavioural interventions. Mental Health Review Journal, 15, 43-53.
Catalano, R. F., Berglund, M. L., Ryan, J. A. M., Lonczak, H. S., \& Hawkins, J. D. (2004). Positive youth development in the United States: Research findings on evaluations of positive youth development programs. Annals of the American Academy of Political and Social Science, 591, 98-124.

Cohen, J. (1992). A power primer. Psychological Bulletin, 112, $155-159$.

Collishaw, S., Maughan, B., Natarajan, L., \& Pickles, A. (2010). Trends in adolescent emotional problems in England: A comparison of two national cohorts twenty years apart. Journal of Child Psychology and Psychiatry and Allied Disciplines, 51, 885-894.

Conduct Problems Prevention Research Group (1999). Initial impact of the Fast Track prevention trial for conduct problems: II. Classroom effects. Journal of Clinical Psychology, 67, 648-657.

Department for Children, Schools and Families (2007). Social and Emotional Aspects of Learning for Secondary Schools (SEAL) guidance booklet. London: DCSF Publications.

Department for Education and Skills (2005). Excellence and enjoyment: Social and emotional aspects of learning. Nottingham: DfES Publications.

Department for Education and Skills (2006). 2020 Vision: Report of the teaching and learning in 2020 review group. Nottinghan: DfES Publications.

Department of Health (2007). Introduction to the national healthy schools programme. London: Department of Health.

Domitrovich, C., Gest, S. D., Jones, D., Gill, S., \& SanfordDeRousie, R. M. (2010). Implementation quality: Lessons learned in the context of the Head Start REDI trial. Early Childhood Research Quarterly, 25, 284-298.

Durlak, J., \& DuPre, E. (2008). Implementation matters: A review of research on the influence of implementation on program outcomes and the factors affecting implementation. Journal of Community Psychology, 41, 327-350.

Durlak, J., Weissberg, R., Dymicki, A., Taylor, R., \& Schellinger, K. (2011). The impact of enhancing students' social and emotional learning: A meta-analysis of school-based universal interventions. Child Development, 82, 405-432.

Durlak, J., Weissberg, R., \& Pachan, M. (2010). A meta-analysis of after-school programs that seek to promote personal and social skills in children and adolescents. American Journal of Community Psychology, 45, 294-309.

Ellis, P. (2010). The essential guide to effect sizes. Cambridge: Cambridge University Press.

Furnham, A., \& Petrides, K. (2003). Trait emotional intelligence and happiness. Social Behavior and Personality, 31, 815-823.

Goleman, D. (1996). Emotional intelligence: Why it can matter more than IQ. London: Bloomsbury.

Graetz, B., Littlefield, L., Trinder, M., Dobia, B., Souter, M., \& Champion, C., et al. (2008).KidsMatter: A population health model to support student mental health and well-being in primary schools. International Journal of Mental Health Promotion, 10, 13-20.

Green, H., McGinnity, A., Melzer, H., Ford, T., \& Goodman, R. (2005). Mental health of children and young people in Great Britain, 2004. London: Office for National Statistics.

Greenberg, M. (2010). School-based prevention: Current status and future challenges. Effective Education, 2, 27-52.

Greenberg, M., Domotrovich, C., Graczyk, P., Zins, J., Domitrovich, C., \& Services, C., et al. (2005). The study of implementation in school-based preventive interventions: Theory, research and practice. Rockville: CMHS.

Heys, B. (Ed.). (2011). Social and emotional education. An international analysis. Santander: Fundacion Botin.

Hughes, J., Cavell, T., Meehan, B., Zhang, D., \& Collie, C. (2005). Adverse school context moderates the outcomes of selective interventions for aggressive children. Journal of Consulting and Clinical Psychology, 2, 731-736. 
Humphrey, N. (2013). Social and emotional learning: A critical perspective. London: Sage.

Humphrey, N., Kalambouka, A., Bolton, J., Lendrum, A., Wigelsworth, M., \& Lennie, C., et al. (2008).Primary Social and Emotional Aspects of Learning (SEAL): Evaluation of small group work. Nottingham: DCSF Publications.

Humphrey, N., Lendrum, A., \& Wigelsworth, M. (2010). Secondary Social and Emotional Aspects of Learning (SEAL): National evaluation. Nottingham: Department for Education.

Humphrey, N., Lendrum, A., \& Wigelsworth, M. (2013). Making the most out of school-based prevention: Lessons from the SEAL programme. Emotional and Behavioural Difficulties (in press).

Kam, C. M., Greenberg, M. T., \& Walls, C. T. (2003). Examining the role of implementation quality in school-based prevention using the PATHS curriculum. Prevention Science, 4, 55-63.

Lendrum, A., \& Humphrey, N. (2012). The importance of studying the implementation of school-based interventions. Oxford Review of Education, 38(5), 635-652.

Lendrum, A., Humphrey, N., Wigelsworth, M., Social and emotional aspects of learning (SEAL) for secondary schools: Implementation difficulties and their implications for school-based mental health promotion. Child and Adolescent Mental Health, http:// dx.doi.org/10.1111/camh.12006, in press.

MacCallum, R. C., Zhang, S., Preacher, K. J., \& Rucker, D. D. (2002). On the practice of dichotomization of quantitative variables. Psychological Methods, 7, 19-40.

Macdonald, W., \& Bower, P. (2000). Child and adolescent mental health and primary health care: Current status and future directions. Current Opinion in Psychiatry, 13, 369-373.

Meltzer, H., Gatward, R., Goodman, R., Ford, T., Ford, F., \& Melzer, $\mathrm{H}$., et al. (2000). Mental health of children and adolescents in Great Britain. International Review of Psychiatry. Vol. 15. London: Office for National Statistics185-187.

Merrell, K. W., \& Gueldner, B. A. (2010). Social and emotional learning in the classroom: Promoting mental health and academic success. London: Guilford Press.

Ofsted (2007). Developing social, emotional and behavioural skills in secondary schools. London: OFSTED.

Parker, J., Creque, E., Barnhart, D., Harris, J., Majeski, S., \& Wood, L., et al. (2004).Academic achievement in high school: Does emotional intelligence matter?. Personality and Individual Differences, 37, 1321-1330.

Petrides, K., Fredrickson, N., \& Furnham, A. (2004). The role of trait emotional intelligence in academic performance and deviant behaviour at school. Personality and Individual Differences, 36, 277-293.
Peugh, J. L., \& Enders, C. K. (2004). Missing data in educational research: A review of reporting practices and suggestions for improvement. Review of Educational Research, 74, 525-556.

Roth, P. (1994). Missing data: A conceptual review for applied psychologists. Personnel Psychology, 47, 537-560.

Rothi, D., \& Leavey, G. (2008). Review mental health help-seeking and young people: A review. Pastoral Care in Education: An International Journal of Personal, Social and Emotional Development, 24, 37-41.

Slee, P., Lawson, M., Russell, A., Askell-Williams, H., Dix, K., \& Owens, L., et al. (2009).Kids Matter: Evaluation final report. Flinders University of South Australia: Centre for Analysis of Educational Futures.

Smith, P., O'Donnell, L., Easton, C., \& Rudd, P. (2007). Secondary Social, Emotional and Behavioural Skills (SEBS) pilot evaluation. London: DCSF Publications.

Social and Character Development Research Consortium. (2010). Efficacy of school wide programs to promote social and character development and reduce problem behaviour in elementary school children. Alexandria.

Southampton Psychology Service (2003). Emotional literacy: Assessment and intervention. London: Nfer-Nelson.

Stallard, P. (2011). Promoting children's well-being. In: D. Skuse, H. Bruce, L. Dowdney, \& D. Mrazek (Eds.), Child psychology and psychiatry: Frameworks for practice (2nd ed.). West Sussex: Wiley-Blackwell.

Stallard, P., Simpson, N., Anderson, S., Hibbert, S., \& Osborn, C. (2007). The FRIENDS Emotional Health Programme: Initial findings from a school-based project. Child and Adolescent Mental Health, 12, 32-37.

Weare, K., \& Nind, M. (2010). Identifying evidence-based work on mental health promotion in schools in Europe: An interim report on the DataPrev Project. Advances in School Mental Health Promotion, 3, 37-45.

Wigelsworth, M., Humphrey, N., \& Lendrum, A. (2011). A national evaluation of the impact of the secondary Social and Emotional Aspects of Learning (SEAL) programme. Educational Psychology, 1, 213-218.

Wilkinson, L. (1999). Statistical methods in psychology journals: Guidelines and explanations. American Psychologist, 54, 594-604.

Wilson, S. J., \& Lipsey, M. W. (2007). School-based interventions for aggressive and disruptive behavior. Update of a metaanalysis. American Journal of Preventative Medicine, 33, S130-S143. 